\title{
Improvement of the Oxidation Resistance of the Single-Crystal Ni-Based TMS-82+ Superalloy by Ni-Al Coatings with/without the Diffusion Barrier
}

\author{
Y. Wu • X. W. Li • G. M. Song • Y. M. Wang • \\ T. Narita
}

Received: 6 February 2010/Revised: 1 July 2010/Published online: 2 September 2010

(C) The Author(s) 2010. This article is published with open access at Springerlink.com

\begin{abstract}
Oxidation behavior of the uncoated base, $\mathrm{Ni}-\mathrm{Al}$ coated and $\mathrm{Re}-\mathrm{Cr}-\mathrm{Ni}$ plus $\mathrm{Ni}-\mathrm{Al}$ coated single-crystal (SC) Ni-based TMS-82+ superalloy is studied under cyclic air at $900{ }^{\circ} \mathrm{C}$ for $200 \mathrm{~h}$ to assess the oxidation resistance. Regardless of the coating processing, $\mathrm{Ni}-\mathrm{Al}$ coating is effective in improving the oxidation resistance due to the formation of a continuous $\alpha-\mathrm{Al}_{2} \mathrm{O}_{3}$ layer in the scale. For the uncoated base superalloy, the mass-gain curves are fitted by a subparabolic relationship, and complex oxide products including predominately $\mathrm{NiO}$, some $\mathrm{CrTaO}_{4}$, $\alpha-\mathrm{Al}_{2} \mathrm{O}_{3}, \mathrm{Cr}_{2} \mathrm{O}_{3}$, a minor of spinels of $(\mathrm{Ni}, \mathrm{Co}) \mathrm{Al}_{2} \mathrm{O}_{4}, \mathrm{AlTaO}_{4}$ and $\theta-\mathrm{Al}_{2} \mathrm{O}_{3}$ are detected. Time-dependence of the oxide growth rate for both coated superalloy with/without the diffusion barrier is explained by the parabolic relationship. The oxide scales consist predominately of $\alpha-\mathrm{Al}_{2} \mathrm{O}_{3}$ and a minor of $\theta-\mathrm{Al}_{2} \mathrm{O}_{3}$. The diffusion barrier of $\sigma$-phase plays a negligible effect on the oxidation resistance during
\end{abstract}

\section{Y. Wu ( $\square)$}

School of Materials Science and Engineering, Shanghai Institute of Technology,

No. 120, Cao Bao Road, Shanghai 200235, People's Republic of China

e-mail: science2008@live.cn

Y. Wu

China Iron \& Steel Research Institute Group, Advanced Technology \& Materials Co., Ltd., No. 76 Xueyuan Nanlu, Haidian, Beijing 100081, People's Republic of China

Y. Wu · Y. M. Wang · T. Narita

Research Group of Interface Control Engineering, Graduate School of Engineering, Hokkaido

University, Kita-13, Nishi-8, Kita-ku, Sapporo 060-8628, Japan

\section{W. Li}

Institute of Materials Physics and Chemistry, College of Sciences, Northeastern University, P.O. Box 104, No. 3-11, Wenhua Road, Shenyang 110004, People's Republic of China

G. M. Song

Department of Materials Science and Engineering, Delft University of Technology,

Mekelweg 2, 2628CD Delft, The Netherlands 
the cyclic exposure environment. The amount of detrimental $\gamma^{\prime}$-phase and topologically close-packed (TCP) phases in the interdiffusion zone in the coated superalloy with the diffusion barrier is greatly reduced compared with that without the diffusion barrier due to the distinct barrier effect limiting diffusion of elements between the bond-coat and the substrate.

Keywords Single-crystal Ni-based superalloy - Diffusion barrier · Coating · Oxidation - Microstructure - Electron probe microanalysis (EPMA)

\section{Introduction}

Ni-based superalloys, particularly directionally solidified single-crystal (SC) superalloys, are receiving considerable attention for high-temperature applications in industrial gas turbine engines and aero-engines because of their high creep strength and good temperature corrosion resistance [1]. In order to satisfy the application for 1300,1500 and $1700{ }^{\circ} \mathrm{C}$-class gas turbines, continuous efforts have been made for improving the oxidation resistance of thermal barrier coatings (TBCs) of Ni-based superalloys. In the case of the TBCs, typical metallic bond-coat layers consists of Al-pack cementation, $\mathrm{PtAl}$ and $\mathrm{MCrAlY}(\mathrm{M}=\mathrm{Co}, \mathrm{Ni}$ or NiCo) for preventing the internal oxidation of substrates, and $\mathrm{Y}_{2} \mathrm{O}_{3}$ stabilized $\mathrm{ZrO}_{2}$ is used as a top-coat material for insulating heat conduction [2]. In commercial engines, the high-pressure turbine blades and vanes exposed to hot gases experience metal surface temperatures of about $1000{ }^{\circ} \mathrm{C}$ which leads to some serious problems for both the bond-coat and top-coat layers and the service life of TBCs is shortened. Due to acceleration of interdiffusion between the substrate and the bond-coat, the precipitation of detrimental phases from the substrate occurs, and the rapid growth of a thermally grown oxide on the bond-coat results in enhancement of the top-coat spallation [3, 4]. Therefore, the limitation of environmental temperature of these high-temperature components requires development of advanced bond-coat materials and coating technologies so as to improve the thermal efficiency by increasing operating temperatures of jet engines and gas turbines. At present, several methods such as diffusion coating, plasma spraying and electron beam physical vapor deposition have been developed to improve the oxidation resistance of TBCs of Ni-based superalloys $[5,6]$. The development of gas turbine materials based on SC Ni-based superalloy has been pushed to the fourth generation by NIMS (National Institute for Materials Science), Japan, in the past decade [7].

A new Re-modified aluminide coating method called self-forming process of coating has been developed previously [8]. Re and $\mathrm{Cr}$ from the substrate form a $\mathrm{Re}-\mathrm{Cr}-\mathrm{Ni}$ ( $\sigma$-phase) layer which acts as a diffusion barrier to suppress the outerdiffusion of Ni from the substrate. The details of the forming process of the $\sigma$-phase are described elsewhere [8-10]. Up to now, only a few of the reports on oxidation behavior of SC Ni-based superalloy containing the diffusion barrier of the $\sigma$-phase layer was reported, although some studies on the oxidation behavior of both uncoated and coated SC Ni-based superalloys have been investigated by several researchers [11-37]. Li et al. [11, 12] reported that the oxidation resistance of a SC 
Ni-based superalloy exposed at $900-1150{ }^{\circ} \mathrm{C}$ is higher than that at $800{ }^{\circ} \mathrm{C}$ because of the formation of a protective inner $\alpha-\mathrm{Al}_{2} \mathrm{O}_{3}$ layer. Kuppusami and Murakami [13] studied an Ir-aluminide and an aluminized Ni-base SC superalloy, TMS-75, under cyclic oxidation at $1100{ }^{\circ} \mathrm{C}$ and suggested that the addition of $\mathrm{Ir}$ to aluminide has been found to improve the protective performance of the aluminides by increasing the surface concentration of $\mathrm{Al}$ and retarding the interdiffusion of the alloying elements. As a consequence, Ir aluminide contains a precipitate free outer zone, a lower amount of $\gamma^{\prime}$ and TCP phases in the diffusion zone. Czech et al. [14] indicated that the INCO 738LC alloy with higher Re content in MCrAlY coatings showed much better oxidation resistance at 950 and $1000{ }^{\circ} \mathrm{C}$ and the influence of the $\mathrm{Re}$ content became much more pronounced at higher temperatures, and the oxidation rate due to $\operatorname{Re}$ addition was lower and the depletion of the Al-rich $\beta$-phase in the coating took more time.

In the present study, the oxidation behavior of a SC Ni-based TMS-82+ superalloy under cyclic air environment at $900{ }^{\circ} \mathrm{C}$ is studied to assess the oxidation resistance of uncoated, $\mathrm{Ni}-\mathrm{Al}$ coated, $\mathrm{Re}-\mathrm{Cr}-\mathrm{Ni}$ plus $\mathrm{Ni}-\mathrm{Al}$ coated superalloys, focusing on the oxidation resistance of the coatings evaluated by analyzing the mass gain and microstructural evolution of the oxide scale as well as the interdiffusion barrier effect of the $\mathrm{Re}-\mathrm{Cr}-\mathrm{Ni}$ phase in the coating.

\section{Materials and Methods}

The experimental materials used in the present study were prepared from the second-generation SC TMS-82+ superalloy (Al:12.24, Co:8.12, Cr:5.42, Hf:0.05, Mo:1.14, Re:0.82, Ta:2.20, W:2.90, Y:004, Zr:0.01, Ni:bal.) (at.\%). Priors to the coating, the specimens were cut into $\phi 12 \times 1 \mathrm{~mm}$ disks from the alloy bars, and the surface was ground to a mirror-like surface by SiC papers up to No. 1200 mesh finish followed by ultrasonic cleaning with acetone in an ultrasonic bath. Apart from the coated specimens, the uncoated base superalloy was used to compare the oxidation behavior.

The coating was obtained by the following processes. One route was to obtain the coated superalloy without the diffusion barrier. The coating was obtained on the specimens by electroplating of Ni followed by Al-pack cementation. A Ni film of about $15 \mu \mathrm{m}$ thickness was electroplated on the specimen surface in a Watt's solution at a bath temperature of $50{ }^{\circ} \mathrm{C}$ for $75 \mathrm{~min}$ with a current density of $20 \mathrm{~mA} /$ $\mathrm{cm}^{2}$ before Ni strike for $30 \mathrm{~s}$ with a current density of $500 \mathrm{~mA} / \mathrm{cm}^{2}$. The high $\mathrm{Al}$ activity pack cementation was carried out in a vacuum of $10^{-3} \mathrm{~Pa}$ at $800{ }^{\circ} \mathrm{C}$ for 20 min by burying the Ni-plated specimens into a mixture of $\mathrm{Al}$ metal powder (15 wt \%), $\mathrm{NH}_{4} \mathrm{Cl}(5 \mathrm{wt} \%)$ as an activator, and $\mathrm{Al}_{2} \mathrm{O}_{3}$ powder as an anti-sintering agent. Another route was performed to obtain the coated superalloy with the diffusion barrier. Priors to Ni electroplating and Al-pack cementation, the diffusion barrier of the $\sigma$-phase was obtained by $\mathrm{Re}-\mathrm{Ni}$ electroplating followed by $\mathrm{Cr}$-pack cementation. The specimen was first electroplated in a $\mathrm{Re}-\mathrm{Ni}$ solution at a bath temperature of $50{ }^{\circ} \mathrm{C}$ for $15 \mathrm{~min}$ with a current density of $20 \mathrm{~mA} / \mathrm{cm}^{2}$, and then Ni-electroplating was performed in a Watt's solution at a bath temperature of $50{ }^{\circ} \mathrm{C}$ 
for $75 \mathrm{~min}$ with a current density of $20 \mathrm{~mA} / \mathrm{cm}^{2}$. The $\mathrm{Cr}$-pack diffusion was carried out in a vacuum of $10^{-6} \mathrm{~Pa}$ at $1280{ }^{\circ} \mathrm{C}$ for $10 \mathrm{~h}$ by embedding the Ni-plated specimens into an $\mathrm{Al}_{2} \mathrm{O}_{3}$ container with a mixture of $\mathrm{Cr}$ vapor source of $\mathrm{Ni}-30 \mathrm{Cr}$ powder as an activator and $\mathrm{Ni}_{2} \mathrm{Al}_{3}$ powder as an anti-sintering agent. After cleaning $\mathrm{Re}-\mathrm{Cr}-\mathrm{Ni}$ coated specimen slightly $\mathrm{Ni}$ electroplating and Al-pack cementation was performed as above process. It is noted that all surfaces of specimens were coated.

Oxidation tests were carried out in air at $900{ }^{\circ} \mathrm{C}$ for $200 \mathrm{~h}$ under a thermal cycling condition. The exposure areas for the base, coated superalloy without and with the diffusion barrier were approximately $3.02,3.17$ and $3.19 \mathrm{~cm}^{2}$, respectively. The specimens were suspended with a platinum wire in an $\mathrm{Al}_{2} \mathrm{O}_{3}$ crucible, and were put into the furnace to expose in air. The specimens were regularly removed from the furnace at intervals of $0-10 \mathrm{~h}$ followed by air cooling to room temperature. The mass change of specimens was measured using a balance (HR-202) with $0.01 \mathrm{mg}$ accuracy at room temperature.

Phase identification of the oxide scales was performed by X-ray diffraction (XRD, D/Max 2500PC Rigaku) using $\mathrm{Cu}\left(K_{\alpha}\right)$ as a target. Surface and crosssectional morphologies were observed using a JEOL scanning electron microscope (SEM, JSM-6500) with energy-dispersive X-ray spectrometry (EDS). The elemental concentration profiles in the cross-sectional layer of the oxides were measured quantitatively by electron probe microanalysis (EPMA, JEOL JXA-8900 M WD/ ED) at $15 \mathrm{kV}$ and $3.0 \times 10^{-8} \mathrm{~A}$. The $\mathrm{Al}_{2} \mathrm{O}_{3}$ standard sample was used for oxygen measurement, and the count of the peaks was used to calculate the intensity of the elements.

\section{Results}

Coating Morphologies and Concentration Profiles of the Elements

The Ni-Al coating of the SC Ni-based superalloy is described in Fig. 1a and b showing the cross-sectional morphology and concentration profiles of the main alloy elements $\mathrm{Ni}, \mathrm{Al}, \mathrm{Co}, \mathrm{Cr}, \mathrm{Mo}, \mathrm{Re}, \mathrm{Ta}$ and $\mathrm{W}$ for the $\mathrm{Ni}-\mathrm{Al}$ coated superalloy. A uniform coating was obtained on the specimen surface, and good adherence between the substrate and coating was observed. It was determined from EPMA result that the coating consisted of an internal Ni-rich layer (I) with about $8 \mu \mathrm{m}$ thickness and an external $\mathrm{Ni}_{2} \mathrm{Al}_{3}$ layer (II) with about $65 \mu \mathrm{m}$ thickness.

A diffusion barrier layer $\mathrm{Re}-\mathrm{Cr}-\mathrm{Ni}$ ( $\sigma$-phase) and a $\mathrm{Ni}_{2} \mathrm{Al}_{3}$ layer formed by applying $\mathrm{Re}-\mathrm{Cr}-\mathrm{Ni}$ plus $\mathrm{Ni}-\mathrm{Al}$ coating of the SC Ni-based superalloy. Figure 2 shows a typical SEM micrograph of cross-sectional morphology and the concentration profiles of the elements by EPMA in the $\mathrm{Re}-\mathrm{Cr}-\mathrm{Ni}$ plus $\mathrm{Ni}-\mathrm{Al}$ coated superalloy. A clear diffusion barrier layer of the $\sigma$-phase with white contrast was obtained in Fig. 2a. Together with the quantitative analysis by EPMA in Fig. 2b, the constituents of the coating were in the order of $\mathrm{Re}-\mathrm{Cr}-\mathrm{Ni}$ diffusion barrier layer (I), $\mathrm{Ni}-\mathrm{Cr}-\mathrm{Al}$ layer (II) and $\mathrm{Ni}_{2} \mathrm{Al}_{3}$ layer (III) from the substrate. The thickness of the $\sigma$-phase, $\mathrm{Ni}-\mathrm{Cr}-\mathrm{Al}$ layer and $\mathrm{Ni}_{2} \mathrm{Al}_{3}$ layer was proximately 8,15 and $65 \mu \mathrm{m}$, respectively. 

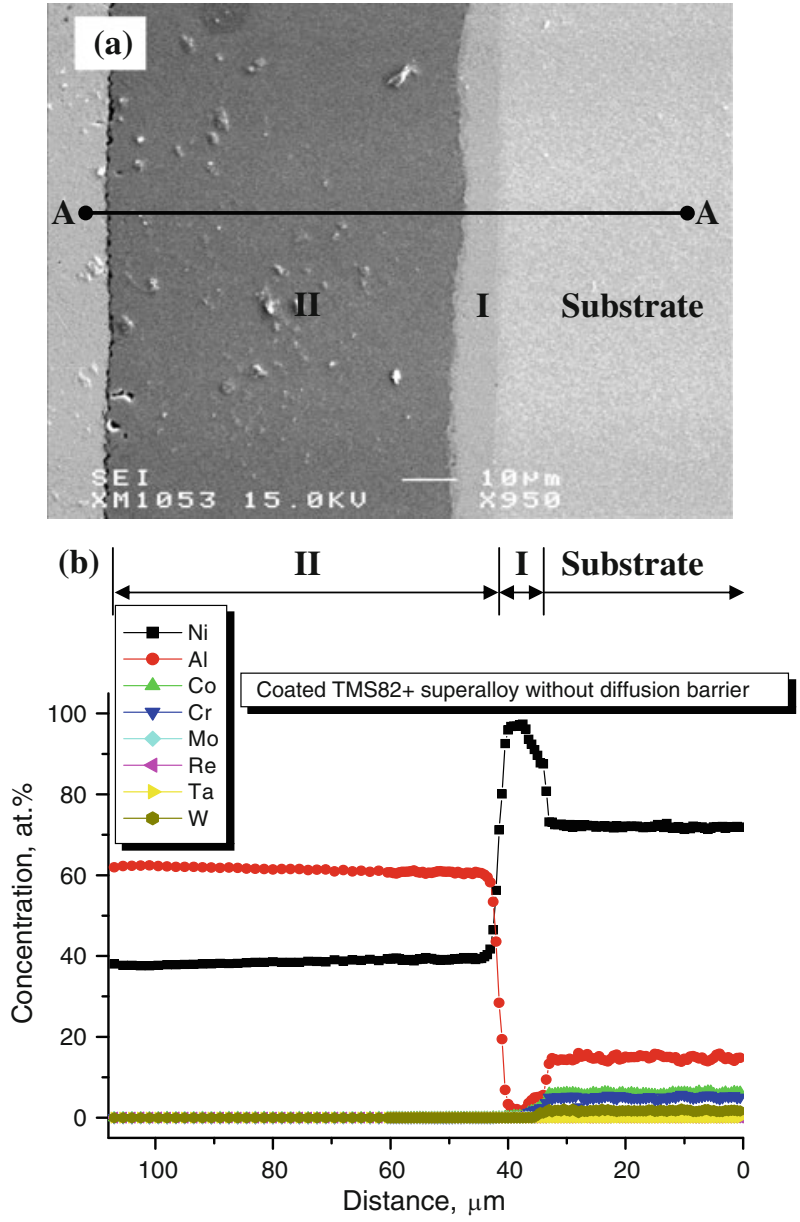

Fig. 1 SEM micrograph of the cross-sectional morphology (a) and concentration profiles (b) of the elements for the $\mathrm{Ni}-\mathrm{Al}$ coated $\mathrm{SC}$ Ni-based superalloy measured along the A-A line. Note: I-Ni-rich layer, $\mathrm{II}_{-} \mathrm{Ni}_{2} \mathrm{Al}_{3}$ layer

\section{Oxidation Kinetics}

The oxidation resistance of the SC Ni-based superalloy was greatly improved by the $\mathrm{Ni}-\mathrm{Al}$ coating regardless of the diffusion barrier. Figure 3 shows the mass gain changes per unit surface area for the uncoated base superalloy [15], $\mathrm{Ni}-\mathrm{Al}$ coated and $\mathrm{Re}-\mathrm{Cr}-\mathrm{Ni}$ plus $\mathrm{Ni}-\mathrm{Al}$ coated superalloy after cyclic oxidation at $900{ }^{\circ} \mathrm{C}$ for $200 \mathrm{~h}$ in air. The coated specimens showed lower mass gains than those of the base superalloy. For example, after $200 \mathrm{~h}$ exposure in air, the mass gains for the specimens with/without the diffusion barrier were 6.0 and $5.0 \mathrm{~g} / \mathrm{m}^{2}$, respectively, which was lower than those of the base superalloy $\left(\sim 6.9 \mathrm{~g} / \mathrm{m}^{2}\right)$. An identical increase trend of mass gain was observed for the both coated specimens at the initial exposure period, however, the mass gain of the base superalloy was much higher. 

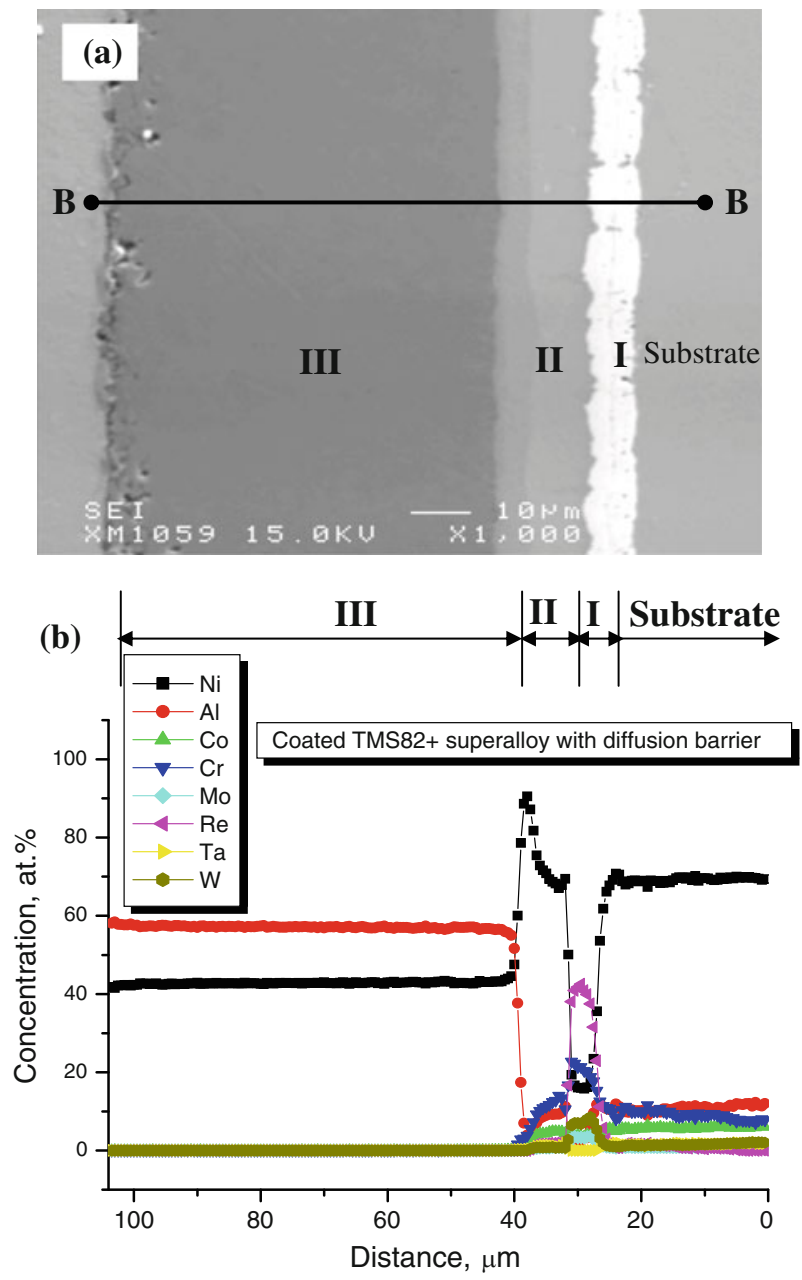

Fig. 2 SEM micrograph of the cross-sectional morphology (a) and concentration profiles (b) of the elements for the $\mathrm{Re}-\mathrm{Cr}-\mathrm{Ni}$ plus $\mathrm{Ni}-\mathrm{Al}$ coated $\mathrm{SC}$ Ni-based superalloy measured along the B-B line. Note: I-diffusion barrier layer, II-Ni-Cr-Al-rich layer, III- $\mathrm{Ni}_{2} \mathrm{Al}_{3}$ layer

The mass gains for the base, the coated specimen with/without the diffusion barrier were $2.8,0$ and $0 \mathrm{~g} / \mathrm{m}^{2}$, respectively, even in the 0 cycle (only heating up and cooling down). The difference for the mass gain between the $\mathrm{Ni}-\mathrm{Al}$ coated and $\mathrm{Re}-\mathrm{Cr}-\mathrm{Ni}$ plus $\mathrm{Ni}-\mathrm{Al}$ coated superalloy increased with extending the exposure time after $70 \mathrm{~h}$.

The mass gain curve for the base superalloy is fitted by a subparabolic relationship, but the time-dependence of the oxide growth rate for both the coated alloys with/without the diffusion barrier follows by the parabolic relationship. The results are shown in Fig. 4. For the base superalloy [15], the initial oxidation rate was rapid, but the rate of mass gain gradually decreased at longer times. Because 


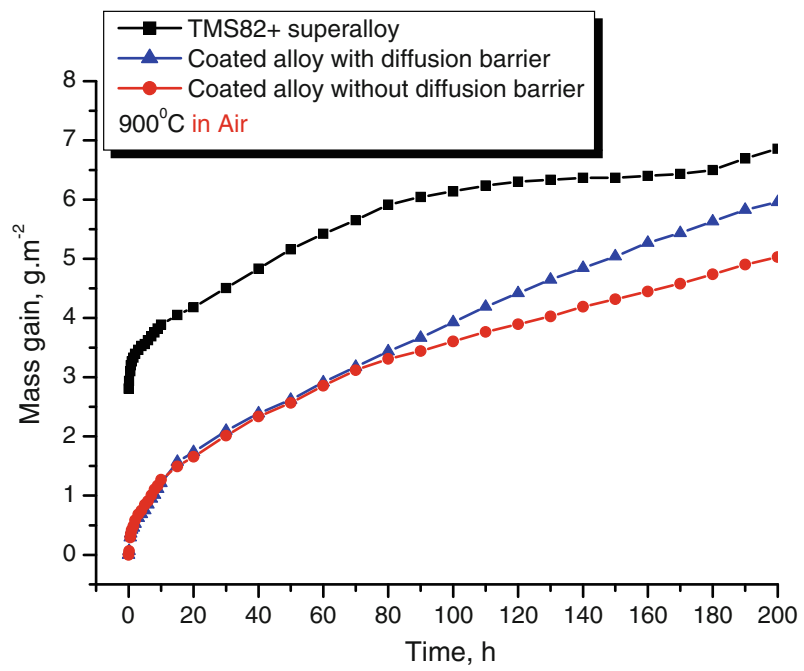

Fig. 3 Oxidation kinetics of the SC Ni-based superalloy in air at $900{ }^{\circ} \mathrm{C}$ for $200 \mathrm{~h}$ under cyclic oxidation

scale spallation was not observed at the present exposure temperature, the lower mass gain could be associated with the formation of a denser scale. The kinetics can be described by examining the growth-time constant (n value), which is found as the exponent in the following rate equation [16]:

$$
(\Delta m / A)=k t^{n}+C
$$

where $\Delta m$ is the mass change, $A$ is the specimen surface area, $k$ is the oxidation rate constant, $t$ is the exposure time and $C$ is a constant. The slope of a log-log plot of above equation gave the $\mathrm{n}$ value, which provides an indication of the mechanism controlling oxidation. The log (mass gain per unit area) as a function of log (time) plots for oxidation in air is shown in Fig. 4a. A value for $n$ of about 0.154 was obtained for the base superalloy exposed at $900{ }^{\circ} \mathrm{C}$ in air above $1 \mathrm{~h}$, which indicates a subparabolic time dependence of growth rate [15]. Similar oxidation kinetics in a SC Ni-based superalloy has been reported by Li et al. [11].

In the case of the coated superalloys, no spallation was observed and the oxidation kinetics obeyed the parabolic law. The squares of mass gain as a function of time plots for oxidation in air are shown in Fig. 4b. The values for $K \mathrm{p}$ of about 0.125 and 0.174 were obtained for the coated SC Ni-based superalloy with/without the diffusion barrier exposed at $900{ }^{\circ} \mathrm{C}$ above $1 \mathrm{~h}$ in air, respectively, which indicates a lower growth rate of the oxides for the former than the latter.

\section{XRD Phase Analysis}

The complex oxide produces on the base superalloy after $200 \mathrm{~h}$ exposures were determined. Figure 5 shows the XRD spectra of the oxide scales formed on the base and coated superalloy without/with the diffusion barrier at $900{ }^{\circ} \mathrm{C}$ after $200 \mathrm{~h}$ cyclic 

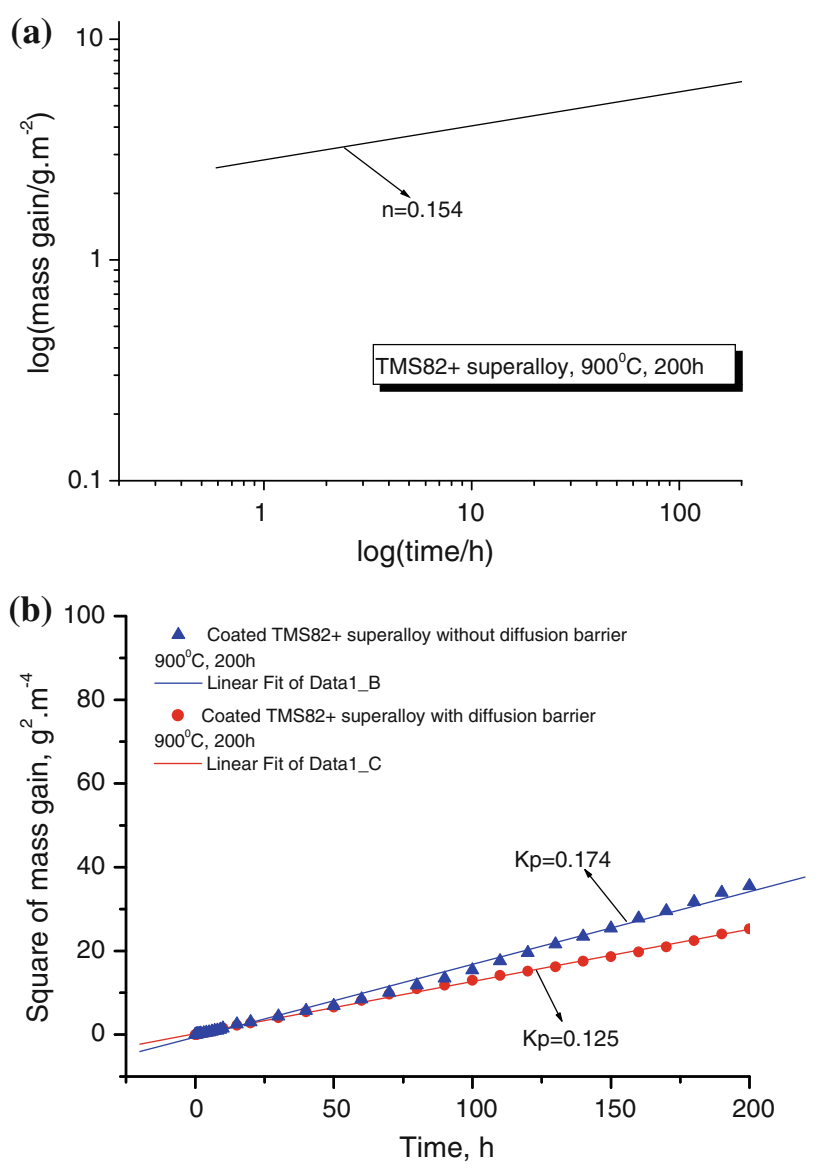

Fig. 4 Logarithm of mass gain per unit area vs logarithm of exposure time for the base alloy (a), and square of the mass gain per unit area as a function of exposure time for the coated alloy with/without the diffusion barrier (b)

exposure in air. On the base superalloy [15], complex oxide products including predominately $\mathrm{NiO}$, some $\mathrm{CrTaO}_{4}, \alpha-\mathrm{Al}_{2} \mathrm{O}_{3}, \mathrm{Cr}_{2} \mathrm{O}_{3}$, a minor of spinels of $(\mathrm{Ni}$, Co) $\mathrm{Al}_{2} \mathrm{O}_{4}, \mathrm{AlTaO}_{4}$ and $\theta-\mathrm{Al}_{2} \mathrm{O}_{3}$ were detected, and the peaks of $\mathrm{NiO}$ showed the strongest intensity. In contrast, for the coated specimens, the oxide products were simple, and two types alumina were detected: $\theta$ and $\alpha-\mathrm{Al}_{2} \mathrm{O}_{3}$. Peaks from $\theta$-, $\alpha-\mathrm{Al}_{2} \mathrm{O}_{3}$ and $\mathrm{NiAl}$ were detected in both coated superalloy regardless of the diffusion barrier, see Fig. $5 \mathrm{~b}$ and c. The intensity of peaks from $\mathrm{NiAl}$ in the oxide scale of the substrate was very strong, indicating a large amount of $\mathrm{NiAl}$ in the coatings. Thus, the formation of $\alpha-\mathrm{Al}_{2} \mathrm{O}_{3}$ greatly decreases the growth of the oxide scale.

\section{Surface Morphology}

The coating on the SC Ni-based superalloy enhanced the growth rate of $\mathrm{Al}_{2} \mathrm{O}_{3}$. Figure 6 shows SEM micrographs of the surface morphology of the oxide scales of 


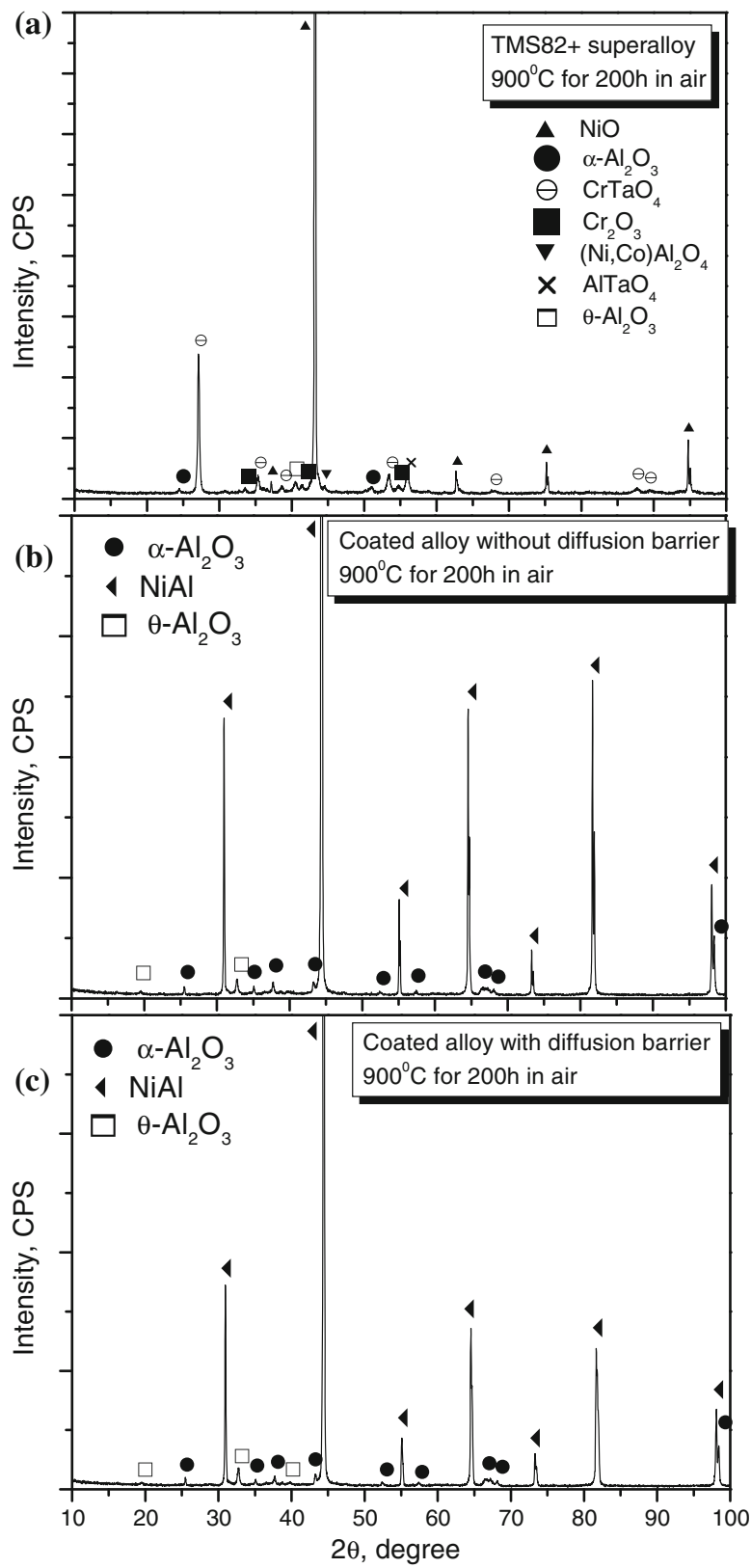

Fig. 5 X-ray diffraction spectra of the oxide scales for the base alloy (a) and the coated alloy without the diffusion barrier (b) and with the diffusion barrier (c) formed at $900{ }^{\circ} \mathrm{C}$ after $200 \mathrm{~h}$ exposure in air

the base and coated SC Ni-based superalloy without/with the diffusion barrier at $900{ }^{\circ} \mathrm{C}$ after $200 \mathrm{~h}$ cyclic exposure. In the base superalloy, see Fig. 6a, the finegrained microstructure of blocky-type oxides covered the surface of the specimens 
Fig. 6 SEM micrographs of the surface morphologies of the oxide scales formed at $900{ }^{\circ} \mathrm{C}$ after $200 \mathrm{~h}$ cyclic oxidation in (a) base alloy, (b) Ni-Al coated and (c) $\mathrm{Re}-\mathrm{Cr}-\mathrm{Ni}$ and $\mathrm{Ni}-\mathrm{Al}$ coated alloy in air
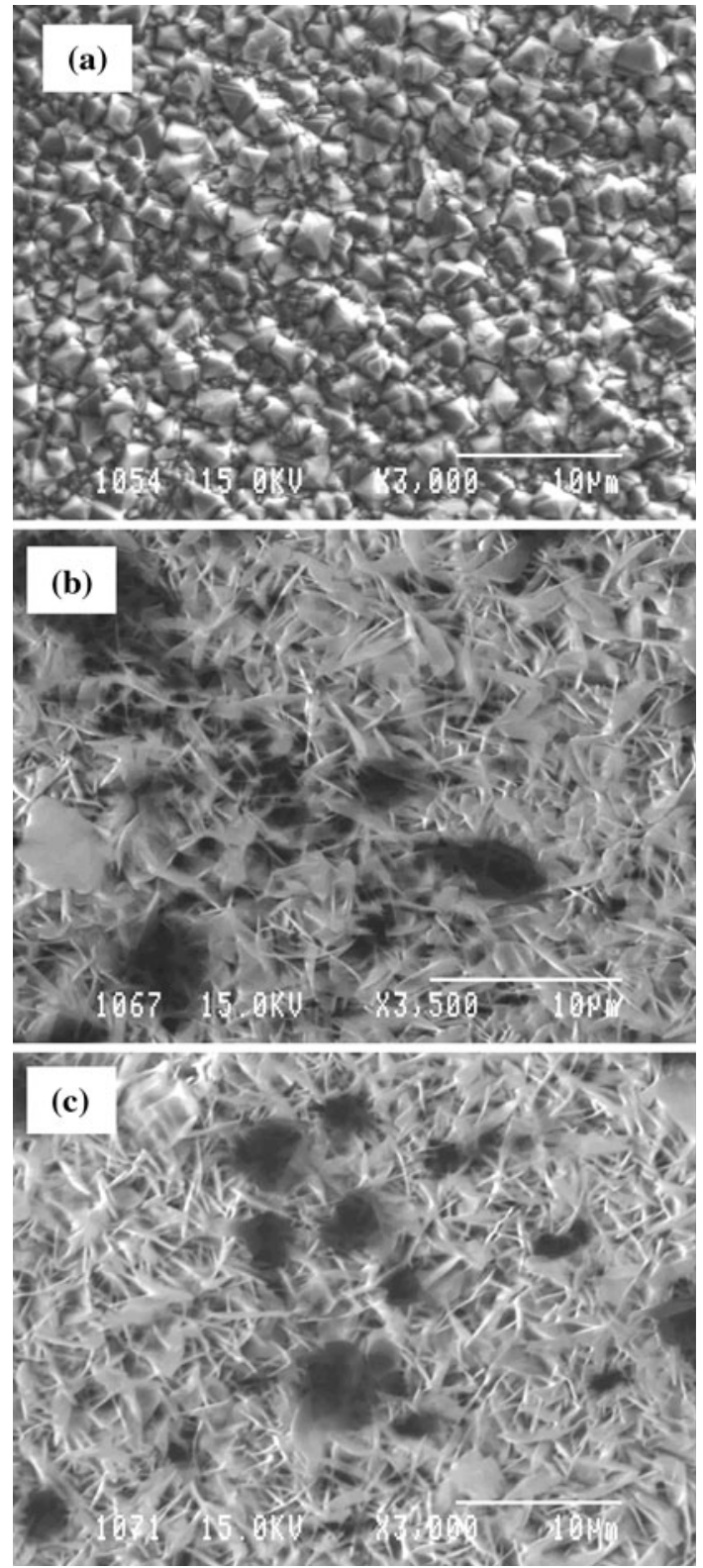

[15]. The grain size of the oxides was $1-3 \mu \mathrm{m}$ diameter. EDS analysis revealed that these oxide particles were rich in oxygen and nickel. As for the coated superalloy, typical morphologies of needle-type oxides were observed on the surface of both specimens. The needle-type oxides were determined to be $\theta-\mathrm{Al}_{2} \mathrm{O}_{3}$. 
Cross-Sectional Morphology and Concentration Profile of the Elements

The scale formed on the base superalloy showed a complex structure [15]. Figure 7a shows a SEM micrograph of the cross-sectional morphology on the base SC Ni-based superalloy after $200 \mathrm{~h}$ cyclic oxidation at $900{ }^{\circ} \mathrm{C}$ in air. The corresponding concentration profiles of the elements by EPMA are shown in Fig. 7b. The thickness of oxide scale was 5-9 $\mu \mathrm{m}$. Main elements $\mathrm{Ni}, \mathrm{O}$ and $\mathrm{Al}$ together with minor elements such as $\mathrm{Cr}$, Ta, Co, Mo, Re and W were detected in the scale. Particularly
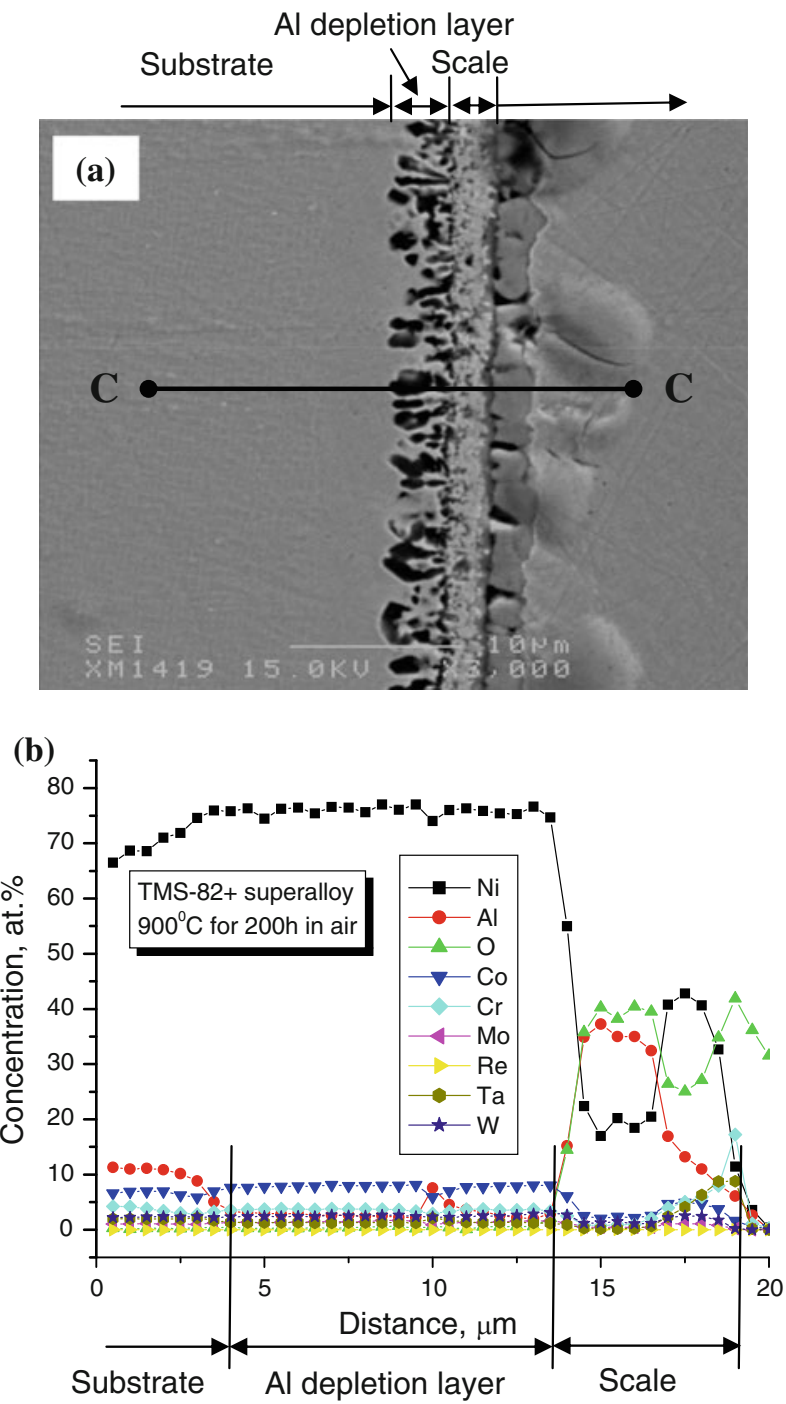

Fig. 7 SEM micrographs of (a) the cross-sectional morphologies of the oxide scales and (b) concentration profiles of the elements measured along the $\mathrm{C}-\mathrm{C}$ line of the base alloy oxidized at $900{ }^{\circ} \mathrm{C}$ after $200 \mathrm{~h}$ in air 
a wide Al depletion zone, approximately $10 \mu \mathrm{m}$ thickness, on the substrate was observed, indicating a great deal of $\mathrm{Al}$ depletion on the substrate. A total of three layers with different chemical compositions were identified for the oxide scale. Starting from the substrate, the oxide scales consisted of Al-rich layer, mixed layer and Ni-rich layer. The existence of the outermost layer of $\mathrm{NiO}$ was common to the Ni-based alloys. The intermediate layer contained main elements of $\mathrm{Ni}, \mathrm{Al}$, and $\mathrm{O}$ with trace elements of $\mathrm{Cr}, \mathrm{Ta}, \mathrm{Co}, \mathrm{Mo}, \mathrm{Re}$ and $\mathrm{W}$. The mixed oxides consisted mainly of $\mathrm{CrTaO}_{4}, \mathrm{AlTaO}_{4}, \mathrm{Cr}_{2} \mathrm{O}_{3}$, spinels and $\mathrm{Al}_{2} \mathrm{O}_{3}$. The innermost layer was $\alpha-\mathrm{Al}_{2} \mathrm{O}_{3}$-rich layer.

A relative simple oxide scale on the surface of the coated specimens was observed. Figure 8 shows a SEM micrograph of the cross-sectional morphology and its corresponding concentration profiles of the elements by EPMA of the coated SC Ni-based superalloy after $200 \mathrm{~h}$ cyclic oxidation at $900{ }^{\circ} \mathrm{C}$ in air. For the coated

(a)
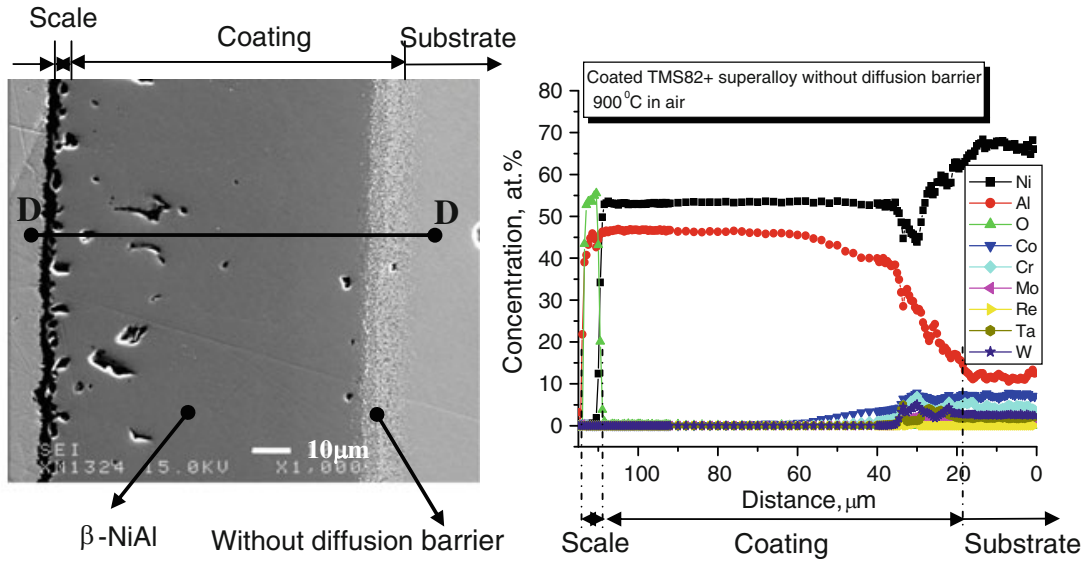

(b)

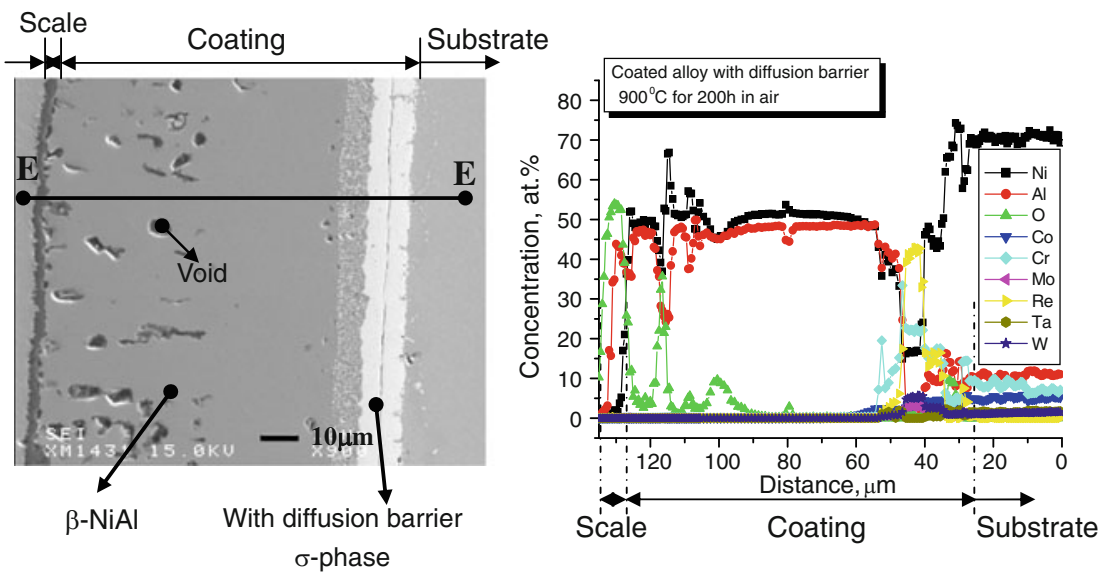

Fig. 8 SEM micrograph of the cross-sectional morphology and concentration profiles of the elements in (a) $\mathrm{Ni}-\mathrm{Al}$ coated alloy measured along the $\mathrm{D}-\mathrm{D}$ line and (b) $\mathrm{Re}-\mathrm{Cr}-\mathrm{Ni}$ and $\mathrm{Ni}-\mathrm{Al}$ coated alloy measured along the E-E line after $200 \mathrm{~h}$ cyclic oxidation at $900{ }^{\circ} \mathrm{C}$ in air 


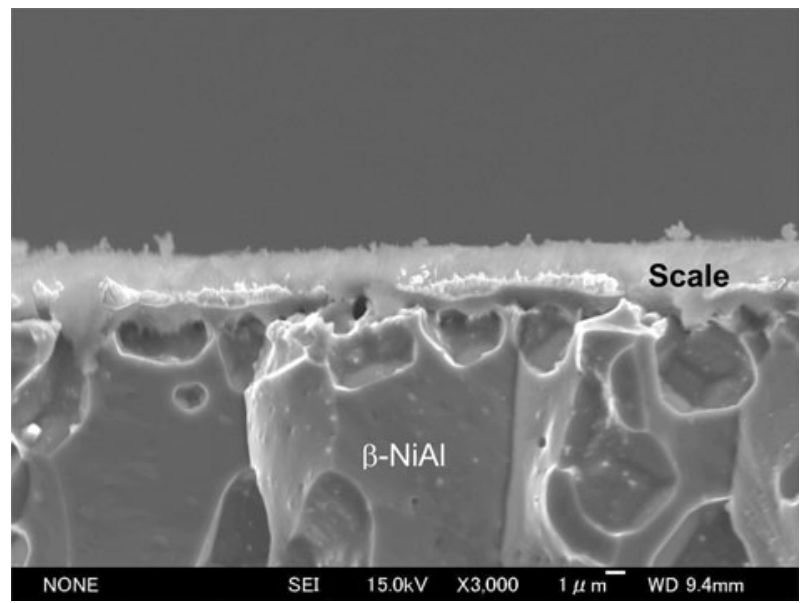

Fig. 9 A higher magnification SEM micrograph of the oxide layer of the cross-sectional morphology in $\mathrm{Re}-\mathrm{Cr}-\mathrm{Ni}$ and $\mathrm{Ni}-\mathrm{Al}$ coated alloy after $200 \mathrm{~h}$ cyclic oxidation at $900{ }^{\circ} \mathrm{C}$ in air

superalloy without the diffusion barrier, see Fig. 8a, three different layers from the substrate were observed: interdiffusion zone, coating and oxide scale. From the results of EPMA, the chemical composition in each layer was determined. The interdiffusion zone consisted mainly of the $\gamma^{\prime}-\mathrm{Ni}_{3} \mathrm{Al}$ and TCP phases, the coating was $\beta$-NiAl, and the oxide scale was composed of $\mathrm{Al}_{2} \mathrm{O}_{3}$ layer. The thickness of the interdiffusion zone, $\beta$-NiAl and $\alpha-, \theta-\mathrm{Al}_{2} \mathrm{O}_{3}$ layer was approximately 15,70 and 3 $\mu \mathrm{m}$, respectively. At $900{ }^{\circ} \mathrm{C}$ exposure, a wide interdiffusion zone of $\gamma^{\prime}-\mathrm{Ni}_{3} \mathrm{Al}$ and TCP phases with a white contrast was evident, which was particularly detrimental to the mechanical properties (ductility and creep-rupture) of the superalloy. These phases are potentially damaging for two reasons: TCP phases can intrude into the substrate and destroy the $\gamma / \gamma^{\prime}$ microstruture, thus reducing creep strength, and they can act as crack initiators because of their brittle nature $[17,18]$.

However, the thickness of the interdiffusion zone decreased for the superalloy containing the diffusion barrier layer, it was about half of that in the coated superalloy without the diffusion barrier, $8 \mu \mathrm{m}$, see Fig. $8 \mathrm{~b}$, which means the amount of $\gamma^{\prime}-\mathrm{Ni}_{3} \mathrm{Al}$ and TCP phases was greatly reduced. Figure 9 shows a higher magnification SEM micrograph of the oxide layer of the cross-sectional morphology in $\mathrm{Re}-\mathrm{Cr}-\mathrm{Ni}$ and $\mathrm{Ni}-\mathrm{Al}$ coated alloy after $200 \mathrm{~h}$ cyclic oxidation at $900{ }^{\circ} \mathrm{C}$ in air. A good adhesion of the scale and the coating was observed without the microcracks. It should be emphasized that there was little change in the structure and concentration profiles of any of the elements in the alloy substrate after oxidation.

\section{Discussion}

As shown in Fig. 1, a thick $\mathrm{Al}_{2} \mathrm{Ni}_{3}$ layer formed on the surface of the $\mathrm{SC}$ Ni-based superalloy after the Al-Ni coating. Applying the $\mathrm{Re}-\mathrm{Cr}-\mathrm{Ni}$ plus $\mathrm{Ni}-\mathrm{Al}$ coating process, a diffusion barrier layer of the $\mathrm{Re}-\mathrm{Cr}-\mathrm{Ni}$ ( $\sigma$-phase) and a $\mathrm{Ni}_{2} \mathrm{Al}_{3}$ layer were 
obtained, see Fig. 2. During exposure at $900{ }^{\circ} \mathrm{C}$, the phase transformation from $\mathrm{Ni}_{2} \mathrm{Al}_{3}$ to $\beta$-NiAl occurred by the following equation under assumptions of stoichiometric compounds.

$$
\mathrm{Ni}_{2} \mathrm{Al}_{3} \rightarrow 2 \mathrm{NiAl}+\mathrm{Al}
$$

As demonstrated in Fig. 8, the outer $\beta$-NiAl layer contains voids, of relatively large size, distributed randomly in the outer layer. Using the molar volumes of $\mathrm{Ni}_{2} \mathrm{Al}_{3}$ $\left(40.5 \mathrm{~cm}^{3} / \mathrm{mol}\right)$ and $\mathrm{NiAl}\left(15.9 \mathrm{~cm}^{3} / \mathrm{mol}\right)$, the volume reduction was estimated to be about $21.5 \%$. Accordingly, the relatively large reduction in volume due to the phase transformation is the reason of the void formation, although there may also be a contribution of the Kirkendall effect due to Al inward diffusion [19]. During oxidation $\mathrm{Al}$ was consumed by the formation of $\mathrm{Al}_{2} \mathrm{O}_{3}$ and $\mathrm{Al}$ diffusion toward the inner layer. The formation of a dense $\alpha-\mathrm{Al}_{2} \mathrm{O}_{3}$ layer resulted in the improvement of oxidation resistance of the superalloy. Regardless of the diffusion barrier, the coated superalloy showed lower mass gains than that of the base superalloy and the scales consisted mainly of $\theta-, \alpha-\mathrm{Al}_{2} \mathrm{O}_{3}$ oxides, indicating much better oxidation resistance in the former. As shown in Figs. 3 and 4, the coated superalloy obeyed the parabolic law. Small values of Kp were obtained, which indicates a lower oxidation rate for the coated superalloy with the diffusion barrier. But, it is not very obvious due to the limited exposure temperature and duration. For the base superalloy, however, the mass gain curve was fitted by a subparabolic relationship. A fast growth rate of the oxides was observed at the initial period for the base superalloy, which contains coarse grains of complex oxides. The subparabolic kinetics occurred at lower temperatures because of grain-boundary mechanisms [16]. The grain-boundary mechanism provides an initially high oxidation rate. As time passes, oxide grain growth occurs. The increase in oxide grain size leads to a reduced density of easy diffusion pathways and, thus, to a slow oxidation rate. The details of the base superalloy exposed at high temperature are described elsewhere [15, 20]. Therefore, the $\mathrm{Al}-\mathrm{Ni}$ coating process is effective in obtaining a dense $\alpha-\mathrm{Al}_{2} \mathrm{O}_{3}$ layer, which is responsible for the improvement of the oxidation resistance.

In order to improve the oxidation resistance of materials in gas turbine engines, the oxidation-resistant coating on the high strength, SC Ni-base superalloy components are applied. The coatings are based on the intermetallic compound $\mathrm{NiAl}$, which is oxidation resistant because under oxidizing conditions a protective scale can be formed, which is composed principally of aluminum oxide. In the present study, the role of the diffusion barrier layer was evident for blocking the interdiffusion of the elements between the substrate and the bond-coat, as shown in Fig. 8b, a reduced amount of $\gamma^{\prime}-\mathrm{Ni}_{3} \mathrm{Al}$ and TCP phases was attained. A diffusion barrier layer of the $\mathrm{Re}-\mathrm{Cr}-\mathrm{Ni}$ phase was relatively stable after exposure at $900{ }^{\circ} \mathrm{C}$, the width of the distribution zone and the density of the $\gamma^{\prime}-\mathrm{Ni}_{3} \mathrm{Al}$ and TCP phases was obviously reduced, indicating an effective barrier for interdiffusion of the alloying elements. For the coated superalloy without the diffusion barrier, however, a wide interdiffusion zone formed, which obviously damages the mechanical properties of the substrate superalloy [21]. During exposure at high temperature, the interdiffusion zone was represented as containing $\gamma^{\prime}-\mathrm{Ni}_{3} \mathrm{Al}$ and TCP phases of the Ni-based superalloy. Extending the duration, further interdiffusion can occur as a result of 
solid-state diffusion across the substrate/coating interface. This additional migration of elements across the substrate-coating interface can sufficiently alter the chemical composition and microstructure of both the bond coat and the substrate in the vicinity of the interface to have deleterious results. Similar study on the effect of the diffusion barrier on interdiffusion of the alloying elements was reported by $\mathrm{Wu}$ et al. [6]. An Ir-Ta modified aluminide coating as an effective diffusion barrier on SC Ni-based superalloy TMS-75 was developed. The Ir-Ta-Al coated TMS-75 had better thermal cyclic oxidation resistance than simply aluminized TMS-75, which was mainly due to a large decrease of detrimental TCP phases in the interdiffusion of solute elements. The precipitation of TCP phase in the Ir-Ta-Al-coated TMS-75 was limited only within $180 \mu \mathrm{m}$ in depth from the surface, whereas in the simply aluminized TMS-75, the depth of distribution of TCP phases was more than $300 \mu \mathrm{m}$, indicating that the $\mathrm{Ir}-\mathrm{Ta}-\mathrm{Al}$ coating functions as an effective diffusion barrier for the alloying elements.

Previous studies demonstrated that Re addition is beneficial for the improvement of the coatings in the superalloy. Liu et al. [22] studied the oxidation behavior of the aluminide diffusion coated the SC Ni-based superalloy DD32M containing 4 wt\% Re in the coating at $1000{ }^{\circ} \mathrm{C}$, and found that Re addition decreased the oxidation rate of the aluminide coating due to the formation of a purer oxide $\mathrm{Al}_{2} \mathrm{O}_{3}$ without $\mathrm{NiAl}_{2} \mathrm{O}_{4}$ and obviously improved the oxidation resistance of the aluminide coating. Additionally, Re addition accelerated the $\theta-\alpha$ phase transformation. Beele et al. [23] indicated that Re addition did not have a significant direct effect on the growth rates of the alumina scale on a Re-containing MCrAlY coating, however, Re had an indirect effect on longterm oxidation performance of the coating, which tended to decrease the extent of $\beta$-phase depletion. In the present case, Re content was higher than 37.5 at. $\%$ in the $\sigma$-phase after $\mathrm{Re}-\mathrm{Cr}-\mathrm{Ni}$ plus $\mathrm{Ni}-\mathrm{Al}$ coating, and Re content retained to 40.2 at. $\%$ after exposure at $900{ }^{\circ} \mathrm{C}$. Thus, the $\sigma$-phase maintained a stable structure.

TBCs generally consist of two coating layers: a metallic bond-coat layer and a ceramic top-coat layer. Development of novel bond-coat materials is a key to improve the service life of TBCs of next-generation gas turbines and jet engines. Generally, simple Al-pack cementation, PtAl or MCrAlY is used as a bond-coat material for preventing the internal oxidation of substrates [2-4]. However, the increase in operating temperature for current turbine systems has brought about serious problems, such as the acceleration of interdiffusion between the substrate and the bond-coat, which may promote the precipitation of detrimental phases in the substrate, and the rapid growth of a thermally grown oxide on the bond-coat surface. In the present study, the diffusion barrier layer of the $\sigma$-phase was obtained to block the interdiffusion of the alloying elements between the substrate and the bond-coat, and reduce the precipitates of the detrimental phases of $\gamma^{\prime}-\mathrm{Ni}_{3} \mathrm{Al}$ and TCP. It is thus expected to further enhance the adherence strength between the top-coat and the bond-coat, and accordingly prolongs the service life of TBCs.

\section{Conclusions}

(1) Regardless of coating processing with/without the diffusion barrier, $\mathrm{Ni}-\mathrm{Al}$ coating is an effective process for improving the oxidation resistance of the SC 
$\mathrm{Ni}$-based superalloy due to the formation of a protective $\alpha-\mathrm{Al}_{2} \mathrm{O}_{3}$ scale. For the uncoated base superalloy, however, the oxide scale consists predominately of $\mathrm{NiO}$, some $\mathrm{CrTaO}_{4}, \alpha-\mathrm{Al}_{2} \mathrm{O}_{3}, \mathrm{Cr}_{2} \mathrm{O}_{3}$, a minor of spinels of ( $\left.\mathrm{Ni}, \mathrm{Co}\right) \mathrm{Al}_{2} \mathrm{O}_{4}$, $\mathrm{AlTaO}_{4}$ and $\theta-\mathrm{Al}_{2} \mathrm{O}_{3}$, which are responsible for poor oxidation resistance.

(2) The mass curves of both coated superalloys with/without the diffusion barrier obey the parabolic relationship. The $\sigma$-phase diffusion barrier plays a negligible effect on the oxidation resistance during the cyclic exposure environment. Because the $\mathrm{Re}-\mathrm{Cr}-\mathrm{Ni}$ acts as a diffusion barrier for both the inward diffusion of $\mathrm{Al}$ and outward diffusion of alloying elements in the alloy substrate, the amount of $\gamma^{\prime}-\mathrm{Ni}_{3} \mathrm{Al}$ and TCP phases in the interdiffusion zone with the diffusion barrier is greatly reduced. The proposed $\mathrm{Re}-\mathrm{Cr}-\mathrm{Ni}$ plus $\mathrm{Ni}-\mathrm{Al}$ coating is promising for applications of the SC Ni-based alloys.

Acknowledgments This work was financially supported by The Program for Professor of Special Appointment (Eastern Scholar) at Shanghai Institutions of Higher Learning, China (No. DF2009-01), and the Innovation Program of Shanghai Municipal Education Commission, China (No. 10ZZ126). Dr. Li is grateful to the Program for New Century Excellent Talents (NCET-07-0162) in University, Ministry of Education, P.R. China, and by the Fundamental Research Funds for the Central Universities of China under Grant No. N090505001. This work described in this paper was also partly supported by an especially promoted project under contract No. 16001004, the Ministry of Education, Culture, Sport, Science and Technology, Japan.

Open Access This article is distributed under the terms of the Creative Commons Attribution Noncommercial License which permits any noncommercial use, distribution, and reproduction in any medium, provided the original author(s) and source are credited.

\section{References}

1. J. K. Tien and T. Caulfield, Superalloys, Supercomposites and Superceramics, (Academic Press, San Diego, 1989).

2. A. Suzuki, F. Wu, H. Murakami, and H. Imai, Science and Technology of Advanced Materials 5, 555 (2004).

3. J. H. Chen and J. A. Little, Surface and Coatings Technology 92, 69 (1997).

4. N. M. Yanar, G. H. Meier, and F. S. Pettit, Scripta Materialia 46, 325 (2002).

5. H. Skulev, S. Malinov, P. A. M. Basheer, and W. Sha, Surface and Coatings Technology 185, 18 (2004).

6. F. Wu, H. Murakami, and A. Suzuki, Surface and Coatings Technology 168, 62 (2003).

7. H. Zhou, Y. Ro, H. Harada, Y. Aoki, and M. Arai, Materials Science \& Engineering A 381, 20 (2004).

8. T. Narita, M. Shoji, Y. Hisamatsu, D. Yoshida, M. Fukumoto, and S. Hayashi, in High-temperature Corrosion Protection (2000), p. 351.

9. T. Narita, K. Z. Thosin, L. Fengqun, S. Hayashi, H. Murakami, B. Gleeson, and D. Young, Materials and Corrosion 56, 923 (2005).

10. T. Narita, T. Izumi, T. Nishimoto, Y. Shibata, K. Z. Thosin, and S. Hayashi, Materials Science Forum 522-523, 1 (2006).

11. M. H. Li, X. F. Sun, J. G. Li, Z. Y. Zhang, T. Jin, H. R. Guan, and Z. Q. Hu, Oxidation of Metals 59, 591 (2003).

12. M. H. Li, X. F. Sun, T. Jin, H. R. Guan, and Z. Q. Hu, Oxidation of Metals 60, 195 (2003).

13. P. Kuppusami and H. Murakami, Surface and Coatings Technology 186, 377 (2004).

14. N. Czech, F. Schmitz, and W. Stamm, Surface and Coatings Technology 68/69, 17 (1994). 
15. Y. Wu and T. Narita, Surface and Coatings Technology 202, 140 (2007).

16. P. Kofstad, High Temperature Corrosion, (Elsevier, New York, 1988), p. 206.

17. M. Reid, M. J. Pomeroy, and J. S. Robinson, Journal of Materials Processing Technology 153-154, 660 (2004).

18. C. M. F. Rae, M. S. Hook, and R. C. Reed, Materials Science \& Engineering A 396, 231 (2005).

19. T. Izumi, T. Nishimoto, and T. Narita, Intermetallics 11, 841 (2003).

20. Y. Wu and T. Narita, Materials and Corrosion 60, 781 (2009).

21. C. T. Sims, in Superalloys II, eds. C. T. Sims, N. S. Stoloff, and W. C. Hagel (Wiley, New York, 1987), p. 217.

22. C. T. Liu, X. F. Sun, H. R. Guan, and Z. Q. Hu, Surface and Coatings Technology 194, 111 (2005).

23. W. Beele, N. Czech, W. J. Quadakkers and W. Stamm, Surface and Coatings Technology 94-95, 41 (1997).

24. Y. H. Zhang, D. M. Knowles, and P. J. Withers, Surface and Coatings Technology 107, 76 (1998).

25. C. T. Liu, X. F. Sun, H. R. Guan, and Z. Q. Hu, Surface and Coatings Technology 197, 39 (2005).

26. J. Angenete and K. Stiller, Materials Science \& Engineering A 316, 182 (2001).

27. J. Angenete, K. Stiller, and V. Langer, Oxidation of Metals 60, 47 (2003).

28. J. Angenete and K. Stiller, Oxidation of Metals 60, 83 (2003).

29. Z. H. Xu, L. M. He, R. Mu, X. H. Zhong, and X. Q. Cao, Vacuum 82, 1251 (2008).

30. F. Q. Lang and T. Narita, Intermetallics 15, 599 (2007).

31. C. Z. Xu, S. M. Jiang, Z. B. Bao, J. Gong, and C. Sun, Corrosion Science 51, 1467 (2009).

32. J. A. Haynes, Y. Zhang, K. M. Cooley, L. Walker, K. S. Reeves, and B. A. Pint, Surface and Coatings Technology 188-189, 153 (2004).

33. Z. H. Xu, R. D. Mu, L. M. He, and X. Q. Cao, Journal of Alloys and Compounds 466, 471 (2008).

34. J. Müller and D. Neuschütz, Vacuum 71, 247 (2003).

35. J. E. Schilbe, Surface and Coatings Technology 133-134, 35 (2000).

36. H. F. Li, S. F. Tao, Z. H. Zhou, L. D. Sun, A. Hesnawi, and S. K. Gong, Surface and Coatings Technology 201, 6589 (2007).

37. Y. Q. Wang and G. Sayre, Surface and Coatings Technology 203, 2186 (2009). 